\title{
Clinical implications of procalcitonin in Kawasaki disease: a useful candidate for differentiating from sepsis and evaluating IVIG responsiveness
}

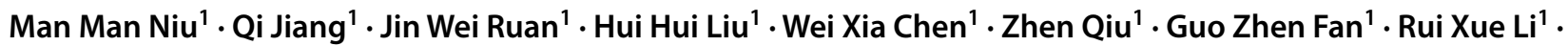 \\ Wei $\mathrm{Wei}^{1} \cdot$ Peng $\mathrm{Hu}^{1}$ (i)
}

Received: 25 January 2021 / Accepted: 26 March 2021 / Published online: 11 April 2021

(c) The Author(s), under exclusive licence to Springer Nature Switzerland AG 2021

\begin{abstract}
Objective Kawasaki disease (KD) is an acute systemic vasculitis and suspected to be triggered by several potential infections in which procalcitonin (PCT) experiences an increase to some extent. However, whether PCT can serve as a useful candidate for differentiating KD from sepsis, and even for predicting incomplete $\mathrm{KD}$, intravenous immunoglobulin (IVIG) nonresponsiveness and coronary artery abnormalities (CAAs) remains unclear.

Methods A total of 254 Chinese KD children were enrolled and divided into 6 subgroups, including complete KD, incomplete KD, IVIG-responsive KD, IVIG-nonresponsive KD, KD with CAAs and KD without CAAs. Blood samples were collected from all subjects within 24-h pre- and 48-h post-IVIG infusion, respectively. PCT, C-reactive protein, erythrocyte sedimentation rate and blood cell counts were detected. In addition, both 261 children with sepsis and 251 healthy children sex- and age-matched with KD children were enrolled in the same period.

Results (1) PCT experienced the highest increase in sepsis patients before antibiotic therapy, followed by acute KD patients and the healthy controls. (2) The proportion of KD patients with a PCT concentration below $0.25 \mathrm{ng} / \mathrm{ml}$ was 11 folds higher than that of sepsis patients. (3) PCT had a sensitivity of $91.7 \%$ and a specificity of $30.3 \%$ at a cutoff value of $>0.15 \mathrm{ng} / \mathrm{ml}$ to predict IVIG nonresponsiveness, and the proportion of IVIG-nonresponders with a PCT concentration of $0.25-0.50 \mathrm{ng} / \mathrm{ml}$ was 2 folds higher than that of IVIG-responders.

Conclusions The PCT concentrations below $0.25 \mathrm{ng} / \mathrm{ml}$ may be useful for discriminating KD from sepsis, and moreover, the PCT concentrations of $0.25-0.50 \mathrm{ng} / \mathrm{ml}$ may be helpful in predicting IVIG nonresponsiveness.
\end{abstract}

Keywords Procalcitonin $\cdot$ Kawasaki disease $\cdot$ Sepsis $\cdot$ Intravenous immunoglobulin $\cdot$ Coronary artery abnormalities

\section{Introduction}

Kawasaki disease (KD) is an acute, self-limited febrile illness and predominantly affects the cardiovascular system in children $<5$ years of age. According to a recent

Man Man Niu, Qi Jiang, Jin Wei Ruan, Hui Hui Liu, Wei Xia Chen, Zhen Qiu, Guo Zhen Fan, Rui Xue Li, Wei Wei and Peng $\mathrm{Hu}$ contributed equally to this work and should be considered cofirstauthors.

Peng $\mathrm{Hu}$

hupeng28@aliyun.com

1 Department of Pediatrics, The First Affiliated Hospital of Anhui Medical University, Hefei, Anhui 230022, People's Republic of China epidemiological survey, an increasing trend in the incidence of KD has been noticed in China, with almost a one-fold increase from 50.5 per 100,000 children in 2008 to 94.7 per 100,000 children in 2017 [1, 2]. Dependent on the 2017 American Heart Association (AHA) guidelines, the diagnostic criteria of KD include fever $\geq 5$ days combined with at least 4 of the 5 principal clinical features. Besides, incomplete KD should be considered in any case with persistent unexplained fever, fewer than 4 of the major clinical features, and compatible laboratory or echocardiographic findings [3]. Coronary artery abnormalities (CAAs) serve as the most important prognostic factor and occur in almost $20 \%$ of KD patients without treatment [4]. High-dose intravenous immunoglobulin (IVIG) plus aspirin is the first-line treatment for not only suppressing systemic inflammation in the acute episode of KD but also decreasing the incidence 
of CAAs to $6.8 \%$ [5]. However, approximately $10 \%$ to $20 \%$ of KD patients still have recrudescent or persistent fever at least $36 \mathrm{~h}$ after completion of the initial IVIG infusion and are termed IVIG nonresponders [2, 4]. To date, the accurate etiology of KD remains unknown, and recent consensus is that an infectious trigger, exaggerated immune response and inflammatory cascades may occur in genetically susceptible children who subsequently develop KD. In a case-control study from Yale University School of Medicine, the detection rate of New Haven coronavirus (HCOV-NH) in respiratory specimens of KD patients was significantly higher than that of the normal control subjects ( $72.7 \%$ versus $4.5 \%)$, with an odds ratio (OR) of 16.0 [6].

Currently, no laboratory test is proved to be specific for the diagnosis of KD apart from the increases in several inflammatory mediators [7-9]. In our previous study comprising 70 children with $\mathrm{KD}$, the mean concentrations of white blood cell (WBC), absolute neutrophil counts (ANC) and C-reactive protein (CRP) were $13.03 \times 10^{9} / 1,8.43 \times 10^{9} / 1$ and $54.38 \mathrm{mg} / \mathrm{l}$, respectively [10]. Although the up-regulated syntheses of inflammatory mediators have been universally recognized in the acute episode of $\mathrm{KD}$, their changes are still ubiquitous in all kinds of infectious diseases. According to the report of Reyes et al. [11], the mean concentrations of WBC, ANC and CRP were $11.02 \times 10^{9} / 1,6.84 \times 10^{9} / 1$ and $66.80 \mathrm{mg} / \mathrm{l}$ in 20 patients with sepsis, respectively, appear to be identical to that in KD patients. Given this background, a better mediator is warranted to both reflect the severity of systemic inflammation and differentially diagnose KD from other infectious diseases.

Procalcitonin (PCT) was primarily isolated 45 years ago as prohormone of calcitonin from $\mathrm{C}$-cell of the thyroid gland and intracellularly degraded by proteolytic enzymes into the active hormone [12]. Although the circulating level of PCT in healthy subjects is far below detection limit, it elevates selectively in the bacterial inflammatory processes and is subjected to a 100-fold increase in the setting of sepsis [13]. Harbarth et al. [14] assessed the diagnostic value of PCT in 78 consecutive patients admitted with acute systemic inflammatory response syndrome (SIRS) and sepsis, and found that median PCT concentrations on admission were $0.6 \mathrm{ng} /$ $\mathrm{ml}$ for SIRS, $3.5 \mathrm{ng} / \mathrm{ml}$ for sepsis and $21.3 \mathrm{ng} / \mathrm{ml}$ for septic shock, respectively; PCT $>1.1 \mathrm{ng} / \mathrm{ml}$ yielded a sensitivity of $97 \%$ and a specificity of $78 \%$ to differentiate SIRS from sepsis, with an area under the receiver operating characteristic curves (AUC) of 0.92. In addition, PCT can be also used for monitoring the response to antimicrobial therapy. Nobre et al. [15] conducted a randomized, controlled, open interventional trial involving 79 patients with sepsis and found that antibiotics for nonlocalized infections could safely be ceased, once PCT fell to $<0.25 \mathrm{ng} / \mathrm{ml}$ or $>90 \%$ from its peak concentration. In the last decade, a limited number of studies on serum PCT have been undertaken in KD patients. By the report of Okada et al. [16], a significant increase of PCT was noted in KD patients $(2.3 \mathrm{ng} / \mathrm{ml})$ compared with the healthy children $(0.2 \mathrm{ng} / \mathrm{ml})$, and moreover, the optimal cutoff value of $3.0 \mathrm{ng} / \mathrm{ml}$ enhanced the prediction rate of CAAs. However, further evidence for the association between PCT and KD should also be provided.

\section{Methods}

\section{Subjects}

The present study was carried out retrospectively in Department of Pediatrics, the First Affiliated Hospital of Anhui Medical University. A total of 254 children having KD were recruited from July 2015 to July 2020. According to the 2017 AHA guidelines [3], the diagnostic criteria for complete KD include the presence of $\geq 5$ days of fever and $\geq 4$ of the following 5 main features: (1) bilateral conjunctival injection without exudates; (2) changes in the oral mucosa, such as erythema and cracking lips, erythema of the pharynx, strawberry tongue; (3) changes in extremities, such as redness and swelling in the acute phase, periungual desquamation in the subacute phase; (4) polymorphous exanthema; and (5) cervical lymphadenopathy ( $\geq 1.5 \mathrm{~cm}$ in diameter), usually unilateral. However, patients with fever for $\geq 5$ days and at least 2 of the main features were diagnosed as having incomplete KD, if no other febrile illnesses could explain the disease process. All patients received the standard therapy for $\mathrm{KD}$, including a single infusion of high-dose IVIG $(2 \mathrm{~g} / \mathrm{kg})$ and aspirin (30-50 mg/kg/d), within 10 days since the onset of fever. IVIG-nonresponsive KD was defined as persistent or recrudescent fever $\geq 36 \mathrm{~h}$ after finishing the initial IVIG infusion. CAAs were defined as a coronary artery having an internal diameter of at least $3 \mathrm{~mm}$ in children $<5$ years or at least $4 \mathrm{~mm}$ in children $\geq 5$ years, or a segment with an internal diameter at least 1.5 times larger than that of an adjacent segment by echocardiogram. In addition, 261 children with sepsis sex- and age-matched with KD children and 251 healthy children sex- and age-matched with KD children were enrolled in the same period. According to the Third International Consensus Definitions for Sepsis and Septic Shock (Sepsis-3), sepsis was defined as life-threatening organ dysfunction caused by a dysregulated host response to infection [17].

\section{Laboratory analysis}

Approval for the present study was acquired from the Medical Ethic Committee of the First Affiliated Hospital of Anhui Medical University and obtained consent from parents of all subjects. Blood samples were collected from all subjects within 24 -h pre- and 48 -h post-IVIG infusion, respectively, 
including WBC, ANC, CRP, erythrocyte sedimentation rate (ESR), red blood cells counts (RBC), hemoglobin ( $\mathrm{Hb})$, platelet count (PLT) and PCT.

\section{Statistical analysis}

Normally distributed continuous data were expressed as mean $\pm \mathrm{SD}$. Comparisons of the frequencies between groups were analyzed using Chi-square tests, and comparisons among groups were made using ANOVA. Serum data were analyzed using the 2 independent samples $t$ test or Mann-Whitney $U$ test and the paired $t$ test or Wilcoxon test for comparison of pre-IVIG to post-IVIG data. Pearson correlation coefficients were reported for PCT and other variables of interest. Cutoff value, sensitivity and specificity of PCT were identified by receiver operating characteristic (ROC) curve. A value of $P<0.05$ was considered significant. Statistical analysis was performed using the statistical package for social studies SPSS version 25.0.

\section{Results}

\section{Patient characteristics}

A total of $254 \mathrm{KD}$ patients (138 males and 116 females) were recruited during the past 5 years, with a mean age of $32.11 \pm 27.35$ months and a range from 2 months to 13 years. In the same period, 261 sepsis patients (146 males and 115 females) were recruited, with a mean age of $36.18 \pm 31.54$ months and a range from 2 months to 13 years. In addition, 251 healthy children (135 males and 116 females) were also recruited, with a mean age of $30.27 \pm 29.05$ months and a range from 2 months to 13 years. No significant differences were observed in age $(f=2.71$, $P>0.05)$ and gender $\left(x^{2}=0.26, P>0.05\right)$ among KD patients, sepsis patients and the healthy controls.

Among $254 \mathrm{KD}$ patients, all 5 classic diagnostic criteria for KD were met in 72 cases $(28.35 \%), 4$ criteria in $104(40.94 \%), 3$ criteria in $48(18.90 \%)$, and 2 criteria in $30(11.81 \%)$. Therefore, 176 patients $(69.29 \%)$ had complete $\mathrm{KD}$, including 101 males and 75 females with a mean age of $32.98 \pm 27.56$ months; 78 patients $(30.71 \%)$ had incomplete $\mathrm{KD}$, including 37 males and 41 females with a mean age of $30.17 \pm 26.94$ months. According to the fever duration after the initial IVIG infusion, $17 \mathrm{KD}$ patients $(6.70 \%)$ including 8 males and 9 females with a mean age of $29.65 \pm 23.54$ months had a mean persistent fever of $72.38 \pm 23.21 \mathrm{~h}$ and were identified as IVIG-nonresponders. In contrast, 237 patients (93.30\%) including 130 males and 107 females with a mean age of $32.29 \pm 27.63$ months were diagnosed as IVIG-responders and exhibited a noted decrease in fever duration $(7.89 \pm 6.89 \mathrm{~h} ; t=11.08$,
$P<0.05)$. Based on the internal diameter of coronary artery, $20 \mathrm{KD}$ patients $(7.87 \%)$ including 13 males and 7 females with a mean age of $36.70 \pm 32.00$ months were defined as having CAAs after IVIG therapy (left coronary artery: $3.09 \pm 0.56 \mathrm{~mm}$; right coronary artery: $3.19 \pm 1.31 \mathrm{~mm}$ ). In contrast, 234 patients (92.13\%) including 125 males and 109 females with a mean age of $31.72 \pm 26.96$ months had normal coronary arteries after IVIG therapy (left coronary artery: $2.04 \pm 0.34 \mathrm{~mm}$, right coronary artery: $1.96 \pm 0.31 \mathrm{~mm})$. The internal diameters of both coronary arteries were significantly larger in KD patients with CAAs (left coronary artery: $t=8.30, P<0.05$; right coronary artery: $t=4.10, P<0.05)$, compared with KD patients without coronary arteritis. Overall, the mean age and male/ female ratio were almost identical between complete KD patients and incomplete KD patients $\left(x^{2}=2.16, P>0.05\right.$; $t=0.76, P>0.05)$, between IVIG-nonresponders and IVIGresponders $\left(x^{2}=0.39, P>0.05 ; t=-0.38, P>0.05\right)$, and between KD patients with CAAs and KD patients without CAAs $\left(x^{2}=1.00, P>0.05 ; t=0.78, P>0.05\right)$.

\section{Laboratory findings}

Blood cell counts and inflammatory mediators in $\mathrm{KD}$ patients, sepsis patients and the healthy controls are shown in Table 1. Significant differences in WBC, ANC, RBC, $\mathrm{Hb}$, PLT, CRP, ESR and PCT were noted among KD patients, sepsis patients and the healthy controls $(P<0.05)$. More specifically, KD patients had a significant increase in WBC, PLT, CRP, ESR and PCT, whereas a significant decrease in $\mathrm{RBC}$ and $\mathrm{Hb}$ compared with the healthy controls regardless of pre-IVIG and post-IVIG therapy $(P<0.05)$; KD patients before IVIG therapy had a significant increase in ANC compared with the healthy controls $(P<0.05)$, whereas no significant difference was found in ANC between KD patients after IVIG therapy and the healthy controls $(P>0.05)$. KD patients had a significant increase in PLT and ESR, whereas a significant decrease in WBC, ANC, RBC, Hb, CRP and PCT compared with sepsis patients regardless of pre-IVIG and post-IVIG therapy $(P<0.05)$. Sepsis patients had a significant increase in WBC, ANC, CRP, ESR and PCT, whereas a significant decrease in $\mathrm{RBC}, \mathrm{Hb}$ and PLT compared with the healthy controls $(P<0.05)$.

As for KD patients, WBC, ANC, CRP, ESR and PCT showed a significant decrease, whereas PLT experienced a significant increase after IVIG therapy $(P<0.05)$. The associations of PCT with blood cell counts and other inflammatory mediators in both KD patients and sepsis patients before therapy are shown in Fig. 1 and Table 2. PCT was positively correlated with CRP, negatively correlated with RBC and PLT in both KD patients and sepsis patients $(P<0.05)$. 
Table 1 Blood cell counts and inflammatory mediators in KD patients, sepsis patients and the healthy controls

\begin{tabular}{|c|c|c|c|c|c|c|c|c|}
\hline & $\begin{array}{l}\text { WBC } \\
\left(\times 10^{9} / 1\right)\end{array}$ & $\begin{array}{l}\text { ANC } \\
\left(\times 10^{9} / 1\right)\end{array}$ & $\begin{array}{l}\text { RBC } \\
\left(\times 10^{12} / 1\right)\end{array}$ & $\begin{array}{l}\mathrm{Hb} \\
(\mathrm{g} / \mathrm{l})\end{array}$ & $\begin{array}{l}\text { PLT } \\
\left(\times 10^{9} / 1\right)\end{array}$ & $\begin{array}{l}\text { CPR } \\
(\mathrm{mg} / \mathrm{l})\end{array}$ & $\begin{array}{l}\text { ESR } \\
(\mathrm{mm} / \mathrm{h})\end{array}$ & $\begin{array}{l}\text { PCT } \\
(\mathrm{ng} / \mathrm{ml})\end{array}$ \\
\hline \multicolumn{9}{|l|}{$\begin{array}{c}\text { KD patients } \\
\quad(n=254)\end{array}$} \\
\hline Pre-IVIG & $13.52 \pm 4.89^{* * \Delta}$ & $8.97 \pm 4.41 * * \Delta$ & $4.21 \pm 0.42^{* \Delta}$ & $111.22 \pm 12.54^{* \Delta}$ & $359.01 \pm 125.62 * * \Delta$ & $61.07 \pm 45.52^{* * \Delta}$ & $61.54 \pm 23.42^{* * \Delta}$ & $2.12 \pm 14.24^{* * \Delta}$ \\
\hline Post-IVIG & $9.76 \pm 3.93^{* * \Delta}$ & $3.56 \pm 3.23^{* \Delta}$ & $4.19 \pm 0.39^{* \Delta}$ & $110.83 \pm 10.67^{* \Delta}$ & $510.97 \pm 160.60^{* * \Delta}$ & $7.47 \pm 10.25^{* * \Delta}$ & $60.57 \pm 20.94 * * \Delta$ & $1.24 \pm 10.59 * * \Delta$ \\
\hline $\begin{array}{l}\text { Sepsis } \\
\quad \text { patients } \\
(n=261)\end{array}$ & $19.62 \pm 10.19^{\Delta \#}$ & $14.25 \pm 8.84^{\Delta \#}$ & $4.34 \pm 0.61^{\triangle \#}$ & $115.49 \pm 17.03^{\triangle \#}$ & $305.89 \pm 121.49^{\Delta \#}$ & $96.82 \pm 66.80^{\triangle \#}$ & $25.24 \pm 17.41^{\Delta \#}$ & $10.24 \pm 21.23^{\Delta \#}$ \\
\hline $\begin{array}{l}\text { Healthy } \\
\text { controls } \\
(n=251)\end{array}$ & $8.26 \pm 2.31^{\text {*\# }}$ & $3.73 \pm 2.24^{* \#}$ & $4.60 \pm 0.48^{\text {*\# }}$ & $123.70 \pm 11.73^{\text {*\# }}$ & $326.59 \pm 98.21^{* \#}$ & $1.35 \pm 0.90^{\text {*\# }}$ & $9.32 \pm 7.79^{* \#}$ & $0.08 \pm 0.05^{* \#}$ \\
\hline
\end{tabular}

Data are presented as the mean \pm SD. ${ }^{*} P<0.05$, significantly difference between pre-IVIG and post-IVIG KD patients; ${ }^{*} P<0.05$, significantly difference between KD patients and the healthy controls; ${ }^{\triangle} P<0.05$, significantly difference between KD patients and sepsis patients; ${ }^{\#} P<0.05$, significantly difference between sepsis patients and the healthy controls

Additionally, PCT was positively correlated with ANC, negatively correlated with $\mathrm{Hb}$ in $\mathrm{KD}$ patients $(P<0.05)$.

In order to evaluate the effectiveness of PCT in differential diagnosis between $\mathrm{KD}$ and sepsis, the distributions of PCT concentrations are depicted (Fig. 2a). Among 254 KD patients, $101(39.76 \%)$ had a PCT concentration below $0.25 \mathrm{ng} / \mathrm{ml}, 64(25.20 \%)$ had a PCT concentration of $0.25-0.50 \mathrm{ng} / \mathrm{ml}, 30(11.81 \%)$ had a PCT concentration of $0.50-1.00 \mathrm{ng} / \mathrm{ml}, 54(21.26 \%)$ had a PCT concentration of $1.00-10.00 \mathrm{ng} / \mathrm{ml}$, and $5(1.97 \%)$ had a PCT concentration of $\geq 10.00 \mathrm{ng} / \mathrm{ml}$. In comparison, among 261 sepsis patients, $9(3.45 \%)$ had a PCT concentration below $0.25 \mathrm{ng} / \mathrm{ml}, 11$ (4.21\%) had a PCT concentration of $0.25-0.50 \mathrm{ng} / \mathrm{ml}, 40$ $(15.33 \%)$ had a PCT concentration of $0.50-1.00 \mathrm{ng} / \mathrm{ml}, 145$ $(55.55 \%)$ had a PCT concentration of $1.00-10.00 \mathrm{ng} / \mathrm{ml}$, and $56(21.46 \%)$ had a PCT concentration of $\geq 10.00 \mathrm{ng} / \mathrm{ml}$. The proportion of KD patients with a PCT concentration below $0.25 \mathrm{ng} / \mathrm{ml}$ was significantly higher than that of sepsis $(P<0.05)$. Therefore, PCT concentrations below $0.25 \mathrm{ng} /$ $\mathrm{ml}$ may be candidates for differential diagnosis between KD and sepsis.

\section{PCT and Clinical classification}

The differences of blood cell counts and inflammatory mediators between complete KD patients and incomplete KD patients are presented in Table 3. No significant differences in WBC, ANC, RBC, Hb, PLT, CRP, ESR and PCT were observed between complete KD patients and incomplete KD patients before IVIG therapy $(P>0.05)$; Furthermore, WBC, ANC, CRP, ESR and PCT showed a significant decrease, whereas PLT experienced a significant increase after IVIG therapy in both complete KD patients and incomplete KD patients $(P<0.05)$.

\section{PCT and IVIG responsiveness}

The differences of blood cell counts and inflammatory mediators between IVIG-responders and IVIG-nonresponders are presented in Table 3. No significant differences in WBC, ANC, RBC, Hb, PLT, CRP, ESR and PCT were observed between IVIG-responders and IVIG-nonresponders before IVIG therapy $(P>0.05)$; ANC and CRP declined to normal, whereas PLT remained significantly higher after IVIG therapy in both IVIG-responders and IVIG-nonresponders $(P<0.05)$; the therapy of IVIG significantly inhibited the increase of WBC, ESR and PCT in IVIG-responders $(P<0.05)$. However, the above 3 inflammatory mediators were at a higher level in IVIG-nonresponders persistently $(P>0.05)$. The ROC curve was generated to determine the best cutoff of WBC, ESR and PCT for prediction of IVIGnonresponders. As shown in Fig. 3, the AUC value for WBC in prediction of IVIG-nonresponders was 0.59 , and the estimated sensitivity and specificity were $50.00 \%$ and $68.60 \%$ with a cutoff of $\mathrm{WBC} \geq 15.61 \times 10^{9} / 1$, respectively. The AUC value for ESR in prediction of IVIG-nonresponders was 0.54 , and the estimated sensitivity and specificity were $66.70 \%$ and $60.60 \%$ with a cutoff of ESR $\geq 66.50 \mathrm{~mm} / \mathrm{h}$, respectively. The AUC value for PCT in prediction of IVIG-nonresponders was 0.55 , and the estimated sensitivity and specificity were $91.70 \%$ and $30.30 \%$ with a cutoff of $\mathrm{PCT}>0.15 \mathrm{ng} / \mathrm{ml}$, respectively.

To assess the value of PCT for the early recognition of IVIG nonresponsiveness, the distributions of PCT concentrations are depicted in both IVIG-responders and IVIGnonresponders (Fig. 2b). Among 17 IVIG-nonresponders, $4(23.53 \%)$ had a PCT concentration below $0.25 \mathrm{ng} / \mathrm{ml}$, $7(41.18 \%)$ had a PCT concentration of $0.25-0.50 \mathrm{ng} / \mathrm{ml}$, $4(23.53 \%)$ had a PCT concentration of $0.50-1.00 \mathrm{ng} / \mathrm{ml}$, and $2(11.76 \%)$ had a PCT concentration of $1.00-10.00 \mathrm{ng} /$ ml. In comparison, among 237 IVIG-nonresponders, 95 (40.09\%) had a PCT concentration below $0.25 \mathrm{ng} / \mathrm{ml}, 57$ 

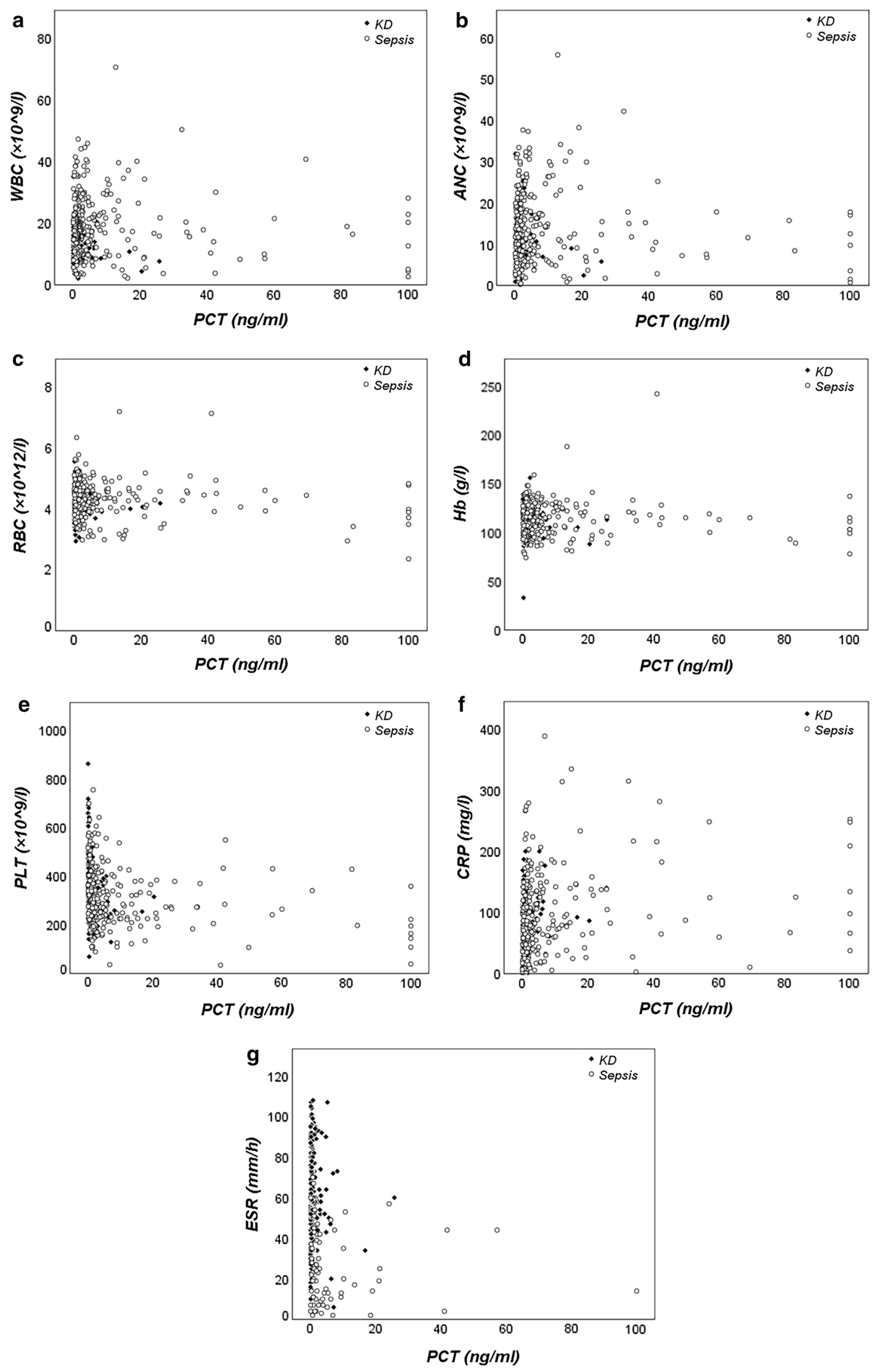

Fig. 1 The associations of PCT with blood cell counts and other inflammatory mediators in both acute KD patients and sepsis patients 
Table 2 The associations of PCT with blood cell counts and other inflammatory mediators in KD patients and sepsis patients $(r, p)$

\begin{tabular}{|c|c|c|c|c|c|c|c|}
\hline PCT & WBC & ANC & $\mathrm{RBC}$ & $\mathrm{Hb}$ & PLT & CPR & ESR \\
\hline (ng/ml) & $\left(\times 10^{9} / \mathrm{l}\right)$ & $\left(\times 10^{9} / 1\right)$ & $\left(\times 10^{12} / 1\right)$ & $(\mathrm{g} / \mathrm{l})$ & $\left(\times 10^{9} / 1\right)$ & $(\mathrm{mg} / \mathrm{l})$ & $(\mathrm{mm} / \mathrm{h})$ \\
\hline \multirow[t]{2}{*}{ KD patients } & & + & - & - & - & + & \\
\hline & $0.128,0.062$ & $0.287,0.000^{*}$ & $-0.149,0.038 *$ & $-0.148,0.036^{*}$ & $-0.425,0.000 *$ & $0.470,0.000 *$ & $0.125,0.079$ \\
\hline \multirow[t]{2}{*}{ Sepsis patients } & & & - & & - & + & \\
\hline & $-0.062,0.316$ & $0.014,0.822$ & $-0.133,0.037 *$ & $-0.028,0.654$ & $-0.218,0.000^{*}$ & $0.232,0.000 *$ & $-0.092,0.444$ \\
\hline
\end{tabular}

+ , a positive correlation; - , a negative correlation; $* P<0.05$
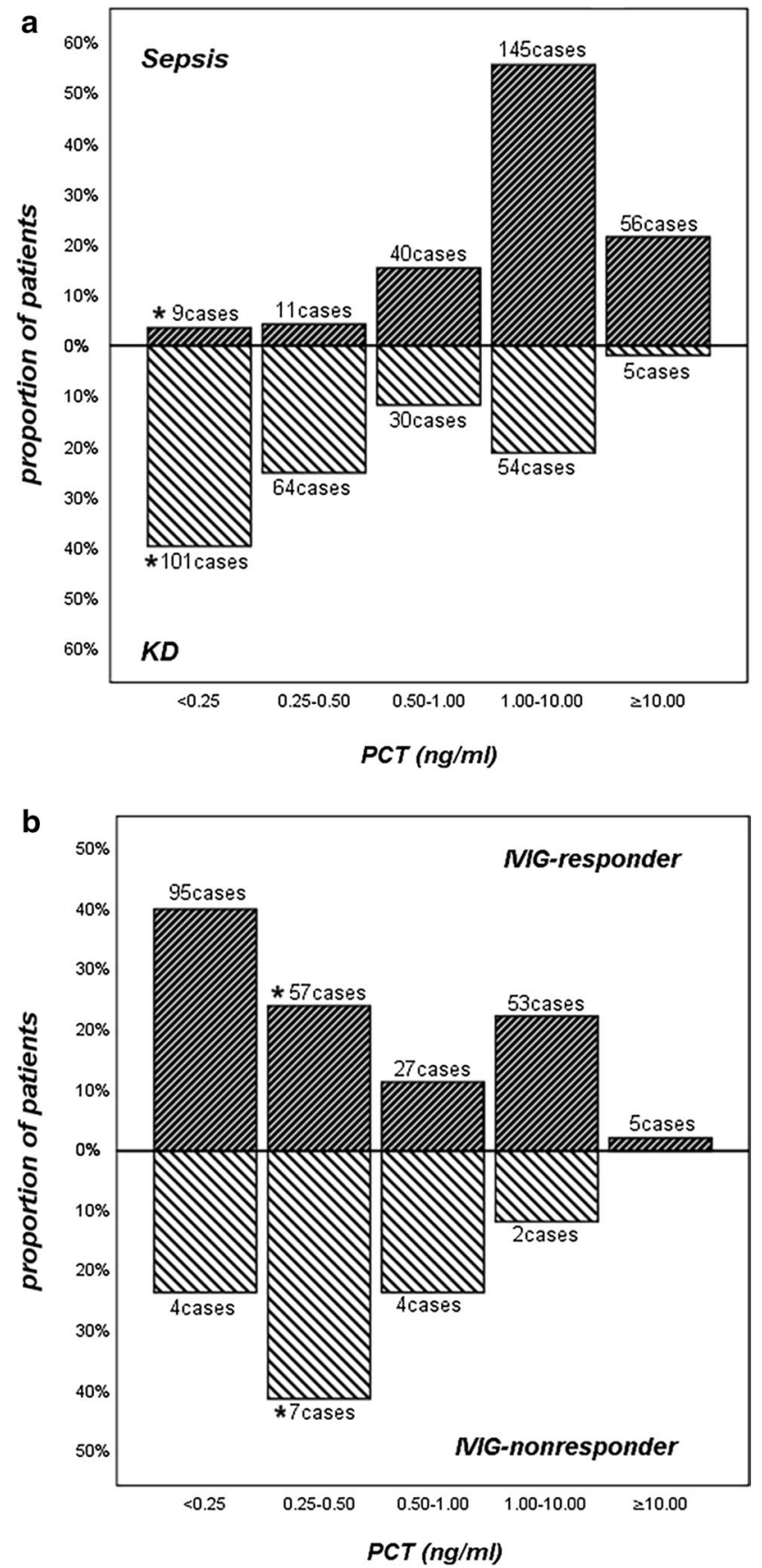

Fig. 2 a The distributions of PCT concentrations in both acute KD patients and sepsis patients. b The distributions of PCT concentrations in both IVIG-nonresponders and IVIG-responders. $* P<0.05$
$(24.05 \%)$ had a PCT concentration of $0.25-0.50 \mathrm{ng} / \mathrm{ml}, 27$ $(11.39 \%)$ had a PCT concentration of $0.50-1.00 \mathrm{ng} / \mathrm{ml}, 53$ $(22.36 \%)$ had a PCT concentration of $1.00-10.00 \mathrm{ng} / \mathrm{ml}$, and $5(2.11 \%)$ had a PCT concentration of $\geq 10.00 \mathrm{ng} / \mathrm{ml}$. The proportion of IVIG-nonresponders with a PCT concentration of $0.25-0.50 \mathrm{ng} / \mathrm{ml}$ was significantly higher than that of IVIG-responders $(P<0.05)$. Therefore, PCT concentrations lying in the $0.25-0.50 \mathrm{ng} / \mathrm{ml}$ range may be candidates for differential diagnosis between IVIG-responders and IVIG-nonresponders.

\section{PCT and Coronary artery involvement}

The differences of blood cell counts and inflammatory mediators between KD patients with and without CAAs are presented in Table 3. No significant differences in WBC, ANC, RBC, Hb, PLT, CRP, ESR and PCT were observed between KD patients with and without CAAs before IVIG therapy $(P>0.05)$; WBC, ANC, CRP, ESR and PCT showed a significant decrease, whereas PLT experienced a significant increase after IVIG therapy in both KD patients with and without CAAs $(P<0.05)$. The associations between internal diameters of coronary arteries with blood cell counts /inflammatory mediators before IVIG therapy are shown in Fig. 4. No correlation of internal diameters of coronary arteries with WBC, ANC, RBC, Hb, PLT, CRP, ESR and PCT was determined, respectively $(P>0.05)$.

\section{Discussion}

PCT is a common serum marker of the inflammatory response and persistently elevated in severe bacterial infection. KD belongs to systemic vasculitis and occurs mainly in children younger than 5 years old. Although the etiology of $\mathrm{KD}$ remains unclear, many current researches have indicated that infection is the most prevalent trigger $[6,18,19]$. In this circumstance, whether PCT can serve as a useful marker for differentiating KD from severe bacterial infection and even guiding antibiotic therapy should be noted by pediatric rheumatologists. In the present study, we compared serum level of PCT among acute KD patients, sepsis patients and 
Table 3 Blood cell counts and inflammatory mediators in patients with different types of KD

\begin{tabular}{|c|c|c|c|c|c|c|c|c|}
\hline $\begin{array}{l}\text { KD patients } \\
(n=254)\end{array}$ & $\begin{array}{l}\text { WBC } \\
\left(\times 10^{9} / 1\right)\end{array}$ & $\begin{array}{l}\text { ANC } \\
\left(\times 10^{9} / 1\right)\end{array}$ & $\begin{array}{l}\mathrm{RBC} \\
\left(\times 10^{12} / 1\right)\end{array}$ & $\begin{array}{l}\mathrm{Hb} \\
(\mathrm{g} / \mathrm{l})\end{array}$ & $\begin{array}{l}\text { PLT } \\
\left(\times 10^{9} / 1\right)\end{array}$ & $\begin{array}{l}\text { CPR } \\
(\mathrm{mg} / \mathrm{l})\end{array}$ & $\begin{array}{l}\text { ESR } \\
(\mathrm{mm} / \mathrm{h})\end{array}$ & $\begin{array}{l}\text { PCT } \\
(\mathrm{ng} / \mathrm{ml})\end{array}$ \\
\hline $\begin{array}{l}\text { Complete } \\
\text { KD } \\
\text { patients } \\
(n=176)\end{array}$ & & & & & & & & \\
\hline Pre-IVIG & $13.35 \pm 4.45^{*}$ & $8.99 \pm 3.86^{*}$ & $4.21 \pm 0.40$ & $111.40 \pm 12.85$ & $353.87 \pm 128.26^{*}$ & $62.56 \pm 42.83 *$ & $64.87 \pm 21.88^{*}$ & $5.39 \pm 27.27 *$ \\
\hline $\begin{array}{l}\text { Post-IVIG } \\
\text { Incom- } \\
\text { plete KD } \\
\text { patients } \\
(n=78)\end{array}$ & $9.89 \pm 4.25^{*}$ & $3.71 \pm 3.70^{*}$ & $4.19 \pm 0.38$ & $110.98 \pm 10.11$ & $499.37 \pm 152.14 *$ & $7.47 \pm 10.73 *$ & $60.21 \pm 20.46^{*}$ & $0.21 \pm 0.38^{*}$ \\
\hline Pre-IVIG & $14.22 \pm 5.53 *$ & $9.17 \pm 4.99 *$ & $4.16 \pm 0.43$ & $110.45 \pm 12.11$ & $367.51 \pm 125.28^{*}$ & $69.63 \pm 48.87 *$ & $66.56 \pm 22.27 *$ & $2.21 \pm 4.10^{*}$ \\
\hline $\begin{array}{l}\text { Post-IVIG } \\
\text { IVIG- } \\
\text { responders } \\
(n=237)\end{array}$ & $9.56 \pm 3.13^{*}$ & $3.24 \pm 1.88^{*}$ & $4.20 \pm 0.42$ & $110.72 \pm 12.02$ & $546.46 \pm 168.74 *$ & $7.76 \pm 9.50^{*}$ & $60.12 \pm 22.79 *$ & $0.16 \pm 0.15^{*}$ \\
\hline Pre-IVIG & $13.60 \pm 4.80^{*}$ & $8.97 \pm 4.25 *$ & $4.21 \pm 0.41$ & $111.32 \pm 12.54$ & $358.34 \pm 124.46^{*}$ & $64.93 \pm 45.54 *$ & $64.99 \pm 21.69 *$ & $4.63 \pm 23.20^{*}$ \\
\hline $\begin{array}{l}\text { Post-IVIG } \\
\text { IVIG-non- } \\
\text { responders } \\
(n=17)\end{array}$ & $9.66 \pm 3.67 *$ & $3.43 \pm 2.89^{*}$ & $4.21 \pm 0.38$ & $111.34 \pm 10.54$ & $513.77 \pm 155.38^{*}$ & $7.49 \pm 10.13^{*}$ & $59.34 \pm 20.90^{*}$ & $0.20 \pm 0.32 *$ \\
\hline Pre-IVIG & $13.97 \pm 5.26$ & $10.09 \pm 4.03 *$ & $4.01 \pm 0.51$ & $107.69 \pm 13.55$ & $355.00 \pm 166.88^{*}$ & $61.91 \pm 32.04 *$ & $70.50 \pm 25.71$ & $0.40 \pm 0.20$ \\
\hline $\begin{array}{l}\text { Post-IVIG } \\
\text { KD patients } \\
\text { without } \\
\text { CAAs } \\
(n=234)\end{array}$ & $11.60 \pm 6.55$ & $5.61 \pm 6.37 *$ & $3.89 \pm 0.42$ & $103.92 \pm 11.70$ & $517.80 \pm 205.90 *$ & $8.64 \pm 13.78^{*}$ & $71.83 \pm 21.30$ & $0.19 \pm 0.30$ \\
\hline Pre-IVIG & $13.67 \pm 4.85^{*}$ & $9.10 \pm 4.24 *$ & $4.18 \pm 0.42$ & $110.72 \pm 12.64$ & $358.52 \pm 126.67 *$ & $66.52 \pm 45.45^{*}$ & $66.02 \pm 21.59 *$ & $4.69 \pm 23.66^{*}$ \\
\hline $\begin{array}{l}\text { Post-IVIG } \\
\text { KD patients } \\
\text { with } \\
\text { CAAs } \\
(n=20)\end{array}$ & $9.78 \pm 3.94 *$ & $3.58 \pm 3.28^{*}$ & $4.18 \pm 0.39$ & $110.61 \pm 10.62$ & $514.24 \pm 153.46^{*}$ & $7.83 \pm 10.72 *$ & $60.35 \pm 21.21^{*}$ & $0.20 \pm 0.34 *$ \\
\hline Pre-IVIG & $13.14 \pm 4.50^{*}$ & $8.40 \pm 4.22 *$ & $4.35 \pm 0.41$ & $115.11 \pm 11.64$ & $353.74 \pm 136.72^{*}$ & $45.44 \pm 31.70^{*}$ & $57.08 \pm 25.45^{*}$ & $1.31 \pm 1.71^{*}$ \\
\hline Post-IVIG & $9.88 \pm 3.89 *$ & $3.36 \pm 2.86^{*}$ & $4.28 \pm 0.41$ & $113.95 \pm 11.65$ & $511.74 \pm 212.66^{*}$ & $4.61 \pm 3.70^{*}$ & $58.00 \pm 20.42 *$ & $0.14 \pm 0.11 *$ \\
\hline
\end{tabular}

Data are presented as the mean $\pm \mathrm{SD}$. $* P<0.05$, significant difference between pre-IVIG and post-IVIG KD patients

the healthy controls and found that it experienced the highest increase in sepsis patients before antibiotic therapy, followed by acute KD patients and the healthy controls. Consistently, two controlled clinical trials from Chongqing and Guangdong, China [20, 21], indicated that serum PCT in acute KD patients had a significant increase compared with the healthy controls $(1.4 \mathrm{ng} / \mathrm{ml} \mathrm{vs} 0.2 \mathrm{ng} / \mathrm{ml})$, whereas it was significantly lower than that in sepsis patients $(1.4 \mathrm{ng} / \mathrm{ml}$ vs $4.1 \mathrm{ng} / \mathrm{ml}$ ). Based on these current evidence, serum PCT in acute KD patients is almost 7-20 folds higher above baseline, whereas 3-5 folds lower than that in sepsis patients. Although the detailed mechanisms of PCT upregulation are still uncertain in acute KD, some studies have demonstrated that inflammatory cytokines secreted by activated monocytes/macrophages may be involved. Balog et al. [22] cultured human peripheral monocytes with Staphylococcus aureus $\left(10^{8} / \mathrm{ml}\right)$ to stimulate the release of tumor necrosis factor-alpha (TNF-alpha) and found that the mean fluorescence intensities of PCT increased from 74 to 131 after an 18-h stimulation by $S$. aureus, which was almost totally abrogated by anti-TNF-alpha monoclonal antibodies. Oberhoffe et al [23] assessed the possible expression of PCT in human peripheral monocytes by reverse transcriptase-polymerase chain reaction (RT-PCR) and revealed that the expression of PCT mRNA showed a maximal 90-fold increase after stimulation by TNF-alpha $(50 \mathrm{ng} / \mathrm{ml})$, a maximal 35 -fold increase by interleukins (IL) $-6(50 \mathrm{ng} / \mathrm{ml})$, a maximal 18 -fold increase by IL- $1 \beta(50 \mathrm{ng} / \mathrm{ml})$, a maximal 15 -fold increase by IL-2 $(50 \mathrm{ng} / \mathrm{ml})$, respectively. Thus, TNF-alpha 


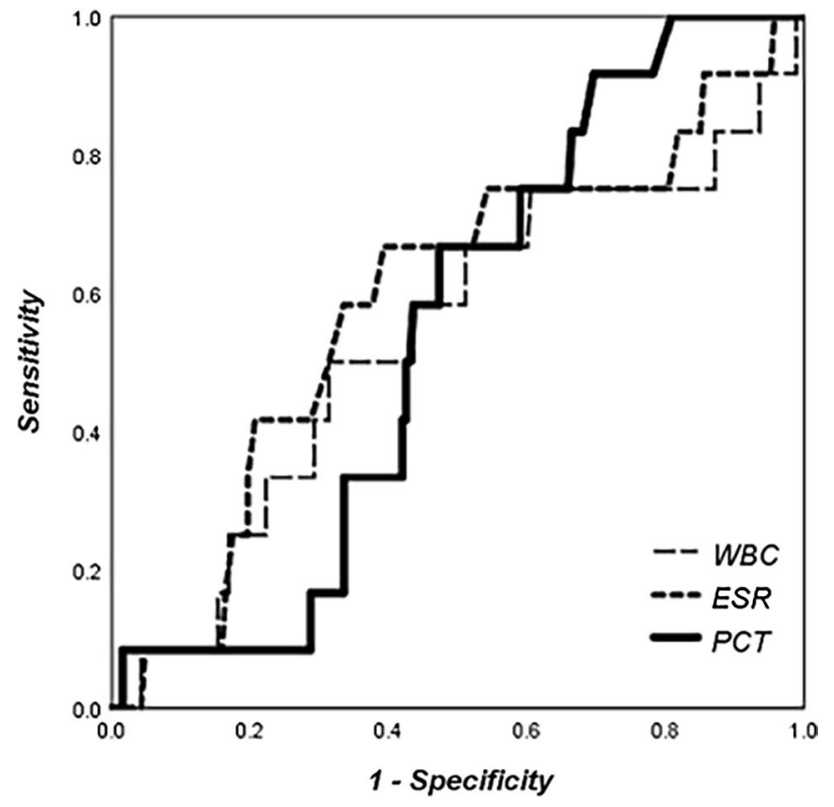

Fig. 3 Receiver operating characteristic (ROC) curve of WBC, ESR, PCT for prediction of IVIG-nonresponders

had the most pronounced stimulatory effect on the expression of PCT in human peripheral monocytes to date.

One main objective of our study was to evaluate the effectiveness of PCT in differential diagnosis between KD and sepsis. In the present study, we observed that the proportion of KD patients with a PCT concentration below $0.25 \mathrm{ng} / \mathrm{ml}$ was 11 folds higher than that of sepsis patients. Based on this finding, PCT concentrations below $0.25 \mathrm{ng} / \mathrm{ml}$ may be useful for discriminating KD from sepsis. Recently, Liu et al. [21] have developed a novel nomogram model to differentiate $\mathrm{KD}$ from sepsis, in which PCT $\leq 0.5 \mathrm{ng} / \mathrm{ml}$ was regarded as a strong predictor for $\mathrm{KD}$ with 57 points, and associated with a 3.41-fold increase in KD probability. However, in a retrospective study encompassing $49 \mathrm{KD}$ patients and 24 sepsis patients from Korea, Lee et al. [24] divided both KD and sepsis patients into $<0.25 \mathrm{ng} / \mathrm{ml}$ group, $0.25-1.0 \mathrm{ng} / \mathrm{ml}$ group and $>1.0 \mathrm{ng} / \mathrm{ml}$ group based on PCT concentrations and found that PCT was not helpful for discriminating KD from sepsis. Because of different identification criteria, analytical methodologies and genetic background, the role of PCT in discriminating KD from sepsis is still controversial. Therefore, further studies of larger sample size and multicenter will be necessary to consolidate our findings.

The other main objective of our study was to assess the value of PCT for the early recognition of IVIG nonresponsiveness. The present study demonstrated that PCT had a sensitivity of $91.7 \%$ and a specificity of $30.3 \%$ at a cutoff value of $>0.15 \mathrm{ng} / \mathrm{ml}$ to predict IVIG nonresponsiveness, and the proportion of IVIG-nonresponders with a PCT concentration of $0.25-0.50 \mathrm{ng} / \mathrm{ml}$ was 2 folds higher than that
Fig. 4 The associations between internal diameters of coronary arteries with blood cell counts /inflammatory mediators before IVIG therapy. No correlation of internal diameters of coronary arteries with WBC, ANC, RBC, Hb, PLT, CRP, ESR and PCT was determined, respectively $(P>0.05)$

of IVIG-responders. In view of the above, PCT concentrations lying in the $0.25-0.50 \mathrm{ng} / \mathrm{ml}$ range may be useful for predicting IVIG nonresponsiveness. Nakamura et al. [25] established a multivariate logistic regression model and revealed that PCT had a sensitivity of $46.4 \%$ and a specificity of $93.9 \%$ at a cutoff value of $>2.18 \mathrm{ng} / \mathrm{ml}$ to predict IVIG nonresponsiveness and possessed the largest AUC of 0.82 than existing 3 refractory prediction scores: Kobayashi score [26], Egami score [27] and Sano score [28]. Consistently, a clinical trial from Boston Children's Hospital, America, indicated that serum PCT $\geq 0.5 \mathrm{ng} / \mathrm{ml}$ was correlated with nonresponsiveness to IVIG and admission to the pediatric intensive care unit (PICU), and moreover, a PCT concentration of $\geq 4.3 \mathrm{ng} / \mathrm{ml}$ showed the most sensitive and specific values for predicting IVIG nonresponsiveness [29]. However, in a prospective study from Sichuan, China, Shao et al. [30] recruited 530 KD patients from January 2015 to March 2019 and discovered that PCT may not be suitable as an independent predictive factor for both initial and repeated IVIG nonresponsiveness. A large controversy exists in these current scattered studies regarding the predictive role of PCT to IVIG nonresponsiveness.

CAAs secondary to KD represent the major contributors to morbidity and mortality in both the acute stage and the long term. The pathological changes of CAAs compass necrotizing arteritis and inflammatory cell infiltration in the first 2 weeks and progress to luminal myofibroblastic proliferation thereafter [31]. Furthermore, several inflammatory cytokines including nuclear factor-kB, IL-1 $\beta$, IL-6, TNFalpha and transforming growth factor- $\beta$ have been reported to participate in CAA onset [32-35]. In acute KD, the overexpression of PCT is associated with elevated inflammatory cytokines. On this background, whether PCT may serve as a predictive factor for CAAs should be elucidated. This study investigated the association between serum PCT and development of CAAs and found that PCT was not helpful in screening CAAs, which was confirmed with the findings of researches from Europe and North America [29, 36]. On the contrary, a retrospective research encompassing $160 \mathrm{KD}$ patients from Japan revealed that PCT had a sensitivity of $67 \%$ and a specificity of $56 \%$ at a cutoff value of $>0.5 \mathrm{ng} /$ $\mathrm{ml}$ to predict CAAs and possessed the highest OR compared with the other inflammatory mediators, such as WBC, ANC, PLT and CRP [37]. Because of different populations and sample sizes, a wide heterogeneity is noted in the predictive role of PCT to CAAs among these current studies, and thus, 

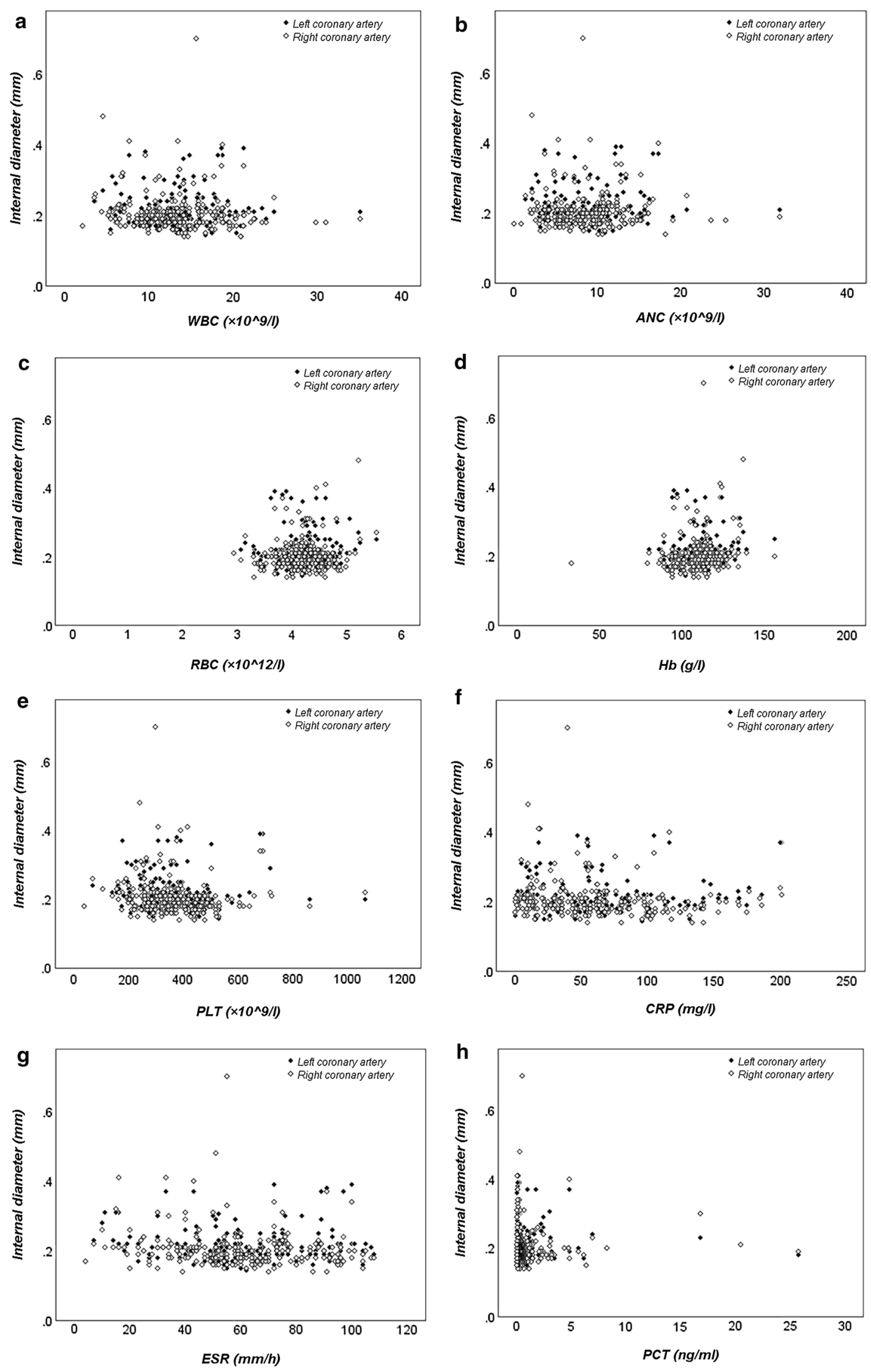
further studies are warranted to focus on this issue more deeply.

Additionally, the present study also assessed the relationship of serum PCT with clinical classification in the course of KD and found that no significant difference was determined in serum PCT between complete KD patients and incomplete KD patients. Lee et al. and Shao et al. [24, 30], respectively, observed 49 KD Korean and 530 KD Chinese, and both found that PCT could not discriminate incomplete KD patients from complete KD patients.

\section{Conclusions and perspectives}

Thus, the PCT concentrations below $0.25 \mathrm{ng} / \mathrm{ml}$ may be useful for discriminating KD from sepsis, and moreover, the PCT concentrations of $0.25-0.50 \mathrm{ng} / \mathrm{ml}$ may be helpful in predicting IVIG nonresponsiveness. However, the present study is still only observational and exploratory. Recently, He et al. [38] have established a new panel containing CRP and PCT, and found that this panel had a sensitivity of $68.10 \%$ and a specificity of $83.40 \%$ at a cutoff value $(\mathrm{CRP}+0.608 * \mathrm{PCT})>23.068$ to predict $\mathrm{CAAs}$ in $\mathrm{KD}$ patients, possessing the largest AUC of 0.773 than CRP and PCT separately. A scoring system comprising the available risk factors plus PCT will be established in our center to enhance the predictive efficacy of KD-associated risks.

Acknowledgements Not applicable.

Authors' contributions $\mathrm{PH}$ conceived and supervised the study; MMN, QJ, JWR, HHL and WXC performed experiments; ZQ and GZF analyzed data; MMN and PH wrote the manuscript; RXL and WW reviewed the manuscripts. All authors approved the final version of the manuscript.

Funding No funding was received for conducting this study.

Data availability The datasets generated during and/or analyzed during the current study are available from the corresponding author on reasonable request.

\section{Declarations}

Conflict of interest The authors declare no conflict of interest.

Ethics approval Approval for the present study was acquired from the Medical Ethic Committee of the First Affiliated Hospital of Anhui Medical University.

Informed consent The consent was obtained from parents of all subjects.

\section{References}

1. Chen JJ, Ma XJ, Liu F, et al. Epidemiologic features of Kawasaki disease in Shanghai from 2008 through 2012. Pediatr Infect Dis J. 2016;35:7-12.

2. Xie LP, Yan WL, Huang M, et al. Epidemiologic features of Kawasaki disease in Shanghai from 2013 through 2017. J Epidemiol. 2020;30:429-35.

3. McCrindle BW, Rowley AH, Newburger JW, et al. Diagnosis, treatment, and long-term management of Kawasaki disease: a scientific statement for health professionals from the American Heart Association. Circulation. 2017;135:e927-99.

4. Makino N, Nakamura Y, Yashiro M, et al. Nationwide epidemiologic survey of Kawasaki disease in Japan, 2015-2016. Pediatr Int. 2019;61:397-403.

5. Newburger JW, Takahashi M, Burns JC, et al. The treatment of Kawasaki syndrome with intravenous gamma globulin. N Engl J Med. 1986;315:341-7.

6. Esper F, Shapiro ED, Weibel C, Ferguson D, Landry ML, Kahn JS. Association between a novel human coronavirus and Kawasaki disease. J Infect Dis. 2005;191:499-502.

7. Downie ML, Manlhiot C, Latino GA, et al. Variability in response to intravenous immunoglobulin in the treatment of kawasaki disease. J Pediatr. 2016;179:124-30.

8. Rigante D, Valentini P, Rizzo D, et al. Responsiveness to intravenous immunoglobulins and occurrence of coronary artery abnormalities in a single-center cohort of Italian patients with Kawasaki syndrome. Rheumatol Int. 2010;30:841-6.

9. Abe J, Ebata R, Jibiki T, Yasukawa K, Saito H, Terai M. Elevated granulocyte colony-stimulating factor levels predict treatment failure in patients with Kawasaki disease. J Allergy Clin Immunol. 2008;122:1008-13.

10. Hu P, Jiang GM, Wu Y, et al. TNF-alpha is superior to conventional inflammatory mediators in forecasting IVIG non response and coronary arteritis in Chinese children with Kawasaki disease. Clin Chim Acta. 2017;471:76-80.

11. Santana Reyes C, García-Muñoz F, Reyes D, González G, Dominguez C, Domenech E. Role of cytokines (interleukin-1 $\beta$, 6,8 , tumour necrosis factor- $\alpha$, and soluble receptor of interleukin-2) and C-reactive protein in the diagnosis of neonatal sepsis. Acta Paediatr. 2003;92:221-7.

12. Maruna P, Nedelníková K, Gürlich R. Physiology and genetics of procalcitonin. Physiol Res. 2000;49(Suppl 1):S57-62.

13. Whang KT, Vath SD, Becker KL, et al. Procalcitonin and proinflammatory cytokine interactions in sepsis. Shock. 2000;14:73-8.

14. Harbarth S, Holeckova K, Froidevaux C, et al. Diagnostic value of procalcitonin, interleukin-6, and interleukin-8 in critically ill patients admitted with suspected sepsis. Am J Respir Crit Care Med. 2001;164:396-402.

15. Nobre V, Harbarth S, Graf JD, Rohner P, Pugin J. Use of procalcitonin to shorten antibiotic treatment duration in septic patients: a randomized trial. Am J Respir Crit Care Med. 2008;177:498-505.

16. Okada Y, Minakami H, Tomomasa T, et al. Serum procalcitonin concentration in patients with Kawasaki disease. J Infect. 2004;48:199-205.

17. Singer M, Deutschman CS, Seymour CW, et al. The third international consensus definitions for sepsis and septic shock (Sepsis-3). JAMA. 2016;315:801-10.

18. Benseler SM, McCrindle BW, Silverman ED, Tyrrell PN, Wong J, Yeung RS. Infections and Kawasaki disease: implications for coronary artery outcome. Pediatrics. 2005;116:e760-6.

19. Rowley AH, Baker SC, Shulman ST, et al. RNA-containing cytoplasmic inclusion bodies in ciliated bronchial epithelium months to years after acute Kawasaki disease. PLoS ONE. 2008;3:e1582. 
20. Si FF, Wu Y, Gao F, Feng S, Liu R, Yi Q. Relationship between IL-27 and coronary arterial lesions in children with Kawasaki disease. Clin Exp Med. 2017;17:451-7.

21. Liu XP, Huang YS, Kuo HC, et al. A novel nomogram model for differentiating Kawasaki disease from sepsis. Sci Rep. 2020;10:13745.

22. Balog A, Ocsovszki I, Mándi Y. Flow cytometric analysis of procalcitonin expression in human monocytes and granulocytes. Immunol Lett. 2002;84:199-203.

23. Oberhoffer M, Stonans I, Russwurm S, et al. Procalcitonin expression in human peripheral blood mononuclear cells and its modulation by lipopolysaccharides and sepsis-related cytokines in vitro. J Lab Clin Med. 1999;134:49-55.

24. Lee NH, Choi HJ, Kim YH. Clinical usefulness of serum procalcitonin level in distinguishing between Kawasaki disease and other infections in febrile children. Korean J Pediatr. 2017;60:112-7.

25. Nakamura N, Muto T, Masuda Y, et al. Procalcitonin as a biomarker of unresponsiveness to intravenous immunoglobulin for Kawasaki disease. Pediatr Infect Dis J. 2020;39:857-61.

26. Kobayashi T, Inoue Y, Takeuchi K, et al. Prediction of intravenous immunoglobulin unresponsiveness in patients with Kawasaki disease. Circulation. 2006;113:2606-12.

27. Egami K, Muta H, Ishii M, et al. Prediction of resistance to intravenous immunoglobulin treatment in patients with Kawasaki disease. J Pediatr. 2006;149:237-40.

28. Sano T, Kurotobi S, Matsuzaki K, et al. Prediction of non-responsiveness to standard high-dose gamma-globulin therapy in patients with acute Kawasaki disease before starting initial treatment. Eur J Pediatr. 2007;166:131-7.

29. Dominguez SR, Martin B, Heizer H, et al. Procalcitonin (PCT) and Kawasaki disease: does PCT correlate with IVIG-resistant disease, admission to the intensive care unit, or development of coronary artery lesions? J Pediatric Infect Dis Soc. 2016;5:297-302.

30. Shao S, Luo C, Zhou K, et al. Predictive value of serum procalcitonin for both initial and repeated immunoglobulin resistance in
Kawasaki disease: a prospective cohort study. Pediatr Rheumatol Online J. 2019;17:78.

31. Orenstein JM, Shulman ST, Fox LM, et al. Three linked vasculopathic processes characterize Kawasaki disease: a light and transmission electron microscopic study. PLoS ONE. 2012;7:e38998.

32. Aeschlimann FA, Yeung RSM. TNF and IL-1 targeted treatment in Kawasaki disease. Curr Treatm Opt Rheumatol. 2016;2:283-95.

33. Matsuda A, Morita H, Unno H, et al. Anti-inflammatory effects of high-dose IgG on TNF-alpha-activated human coronary artery endothelial cells. Eur J Immunol. 2012;42:2121-31.

34. Shimizu C, Jain S, Davila S, et al. Transforming growth factorbeta signaling pathway in patients with Kawasaki disease. Circ Cardiovasc Genet. 2011;4:16-25.

35. Zhou Y, Wang S, Zhao J, Fang P. Correlations of complication with coronary arterial lesion with VEGF, PLT, D-dimer and inflammatory factor in child patients with Kawasaki disease. Eur Rev Med Pharmacol Sci. 2018;22:5121-6.

36. Catalano-Pons C, André MC, Chalumeau M, Guérin S, Gendrel D. Lack of value of procalcitonin for prediction of coronary aneurysms in Kawasaki disease. Pediatr Infect Dis J. 2007;26:179-80.

37. Yoshikawa H, Nomura Y, Masuda K, et al. Serum procalcitonin value is useful for predicting severity of Kawasaki disease. Pediatr Infect Dis J. 2012;31:523-5.

38. He YW, Tian J, Yi QJ, et al. Predictive values of serum procalcitonin and $\mathrm{C}$ reactive protein on coronary artery lesion in children with Kawasaki disease. Chin J Obstet Gynecol Pediatr (Electron Ed). 2018;14:31-7. https://doi.org/10.3877/cma.j.issn.1673-5250. 2018.01.005.

Publisher's Note Springer Nature remains neutral with regard to jurisdictional claims in published maps and institutional affiliations. 